\title{
The Global Rise of E-GOVERNMENT AND ITS SECURITY IMPLICATIONS
}

JEREMY MILLARD

Contents

Introduction

Web on the March

The Known Unknowns of Cybersecurity 4

Privacy 6

Trust

Data Security

Loss of Data Control

The Mother of All Known Unknowns-Human Behavior

Government Loses Control-Who Is Now in Charge and

Why It Matters

Who Gets In and What Gets Out When Government

Opens the Door?

Back to Basics: Trust, Transparency, and Accountability

How to Swim in an Ocean of Insecure Data

\section{Introduction}

The business of government is, at core, all about public sector data, information, and knowledge being created, altered, moved around, and deployed to meet the needs of society. E-government digitizes some or all of these processes and the outcomes produced, potentially transforming them in ways not always predicted or desired, whether 
for the internal operations of the public sector or for the users of public services and facilities. These unintended consequences can be problematic. For example, they can pose profound challenges to cybersecurity in terms of unauthorized access to, or use of, data and public sector information. Public sector managers need to be just as aware of these unintended consequences as they are of those they expect when e-government is introduced.

Now, do not misunderstand me. E-government is a very good thing and has many clear and documented benefits. For example, there is a lot of evidence that digitizing back-office processes can lead to significant cost savings for government through more efficient and rational processes, joining up administrations to share and save resources, better design and targeted services, and more intelligent and evidencebased policy development with greater impact. As illustrated in a 2011 article in the European Journal of ePractice, e-government also has a lot to offer in tackling the financial and economic crisis. In the frontoffice, e-government services undoubtedly provide users with better, more convenient, time-saving services, available 24-7. Digitization encourages transparency, openness, and participation, and provides tools for users to get involved in designing and consuming services more appropriate to their individual needs.

For example, a 2010 survey from TechAmerica, an information technology (IT) trade association, shows how federal agencies and departments in the United States have increased efforts to publish data sets and utilize social media tools as part of the Obama Administration's push for transparency, yet continue to struggle with cybersecurity, IT infrastructure, and workforce issues. The shift toward a more open government has created threats as well as opportunities. According to the survey, some chief information officers (CIOs) see "millions of malicious attempts per day to access their networks"-from recreational hackers to sophisticated cyber-criminals.

This chapter illustrates some of the issues of moving public sector information online, showing that these have both direct and indirect ramifications across the large canvas of e-government areas often not considered. For example, many governments are making the mistake of trying to set security systems too high for the functionalities deployed, resulting in a waste of resources that could have been used to shore up more vulnerable systems. There have been many 
failed attempts to introduce sophisticated Public Key Infrastructure (PKI) and digital signature systems when simple passwords or PIN codes would suffice. The lesson is to take security and data protection extremely seriously and treat it as the most pressing technical challenge, but at the same time approach these issues incrementally and proportionally given that there is always a trade-off between increased security and usage. The approach to take is to build in security and data protection from the very start of any e-government initiative.

\section{Web on the March}

Since 2004 the evolution of the World Wide Web has moved from Web 1.0 (consisting of Internet websites and webpages, e-mail, instant messaging, short message service (SMS), simple online discussion, etc.) to Web 2.0 that also allows users to provide and manipulate content and get directly involved. Web 2.0 sites typically have an "architecture of participation" that encourages users to add value to the application as they use it, for example, through social media dialogue around user-generated content in a virtual community. There is also much discussion about the Web 3.0 evolution toward wide-scale ubiquitous seamless networks (sometimes called grid computing), networked and distributed computing, open ID, open semantic web, large-scale distributed databases, and artificial intelligence.

Some are also looking forward to Web 4.0 as the global semantic web (i.e., methods and technologies that allow machines to understand the meaning, or "semantics," of information on the web), including the use of statistical, machine-constructed semantic tags and algorithms. According to Tim Berners-Lee, the "father" of the Internet, we are indeed on the verge of the age of the semantic web that exploits the Internet of data rather than the Internet of documents we now have. This will enable intelligent uses of the Internet like asking questions rather than simply searching for key words, as well as more automatic data exchanges between databases, data mining, and similar uses.

E-government is affected by the march of the web with increasing focus on the Government 2.0 paradigm. This concentrates much more on the demand side, on user empowerment and engagement, as well as on benefits and impacts that address specific societal challenges, rather than simply providing administrative services online. 
This is to be achieved by supporting the real transformation of governance arrangements away from silo and government centricity toward becoming more user centric and user driven. As noted by Millard in 2010, users and other legitimate stakeholders are being invited more openly into a participative and empowering relationship with government in relation to service design and delivery, the workings and arrangements of the public sector and public governance more widely, as well as public policy and decision making.

To this effect, tremendous e-government progress has been made over the last 10 to 15 years during which time the use of information communication technology (ICT) in the public sector has moved from being largely a concern of separate ministries in digitizing their records and processes, to one where ICT is used to join up ministries, reengineer processes, and offer many new services to citizens and businesses. E-government has become a top priority for governments around the world and a major focus of investment. This can be measured in the steady growth of the supply-side availability of e-government services across all countries since 2000. For example, according to ongoing benchmarking reports led by Capgemini, a consultancy, full online availability of a basket of the most common 20 e-government services in Europe increased from 20\% in 2001 to $82 \%$ in 2010, while online sophistication increased from $45 \%$ in 2001 to $90 \%$ in 2010 . Globally, the 2010 UN benchmarking survey "finds that citizens are benefiting from more advanced e-service delivery, better access to information, more efficient government management and improved interactions with governments, primarily as a result of increasing use by the public sector of information and communications technology" (p. 59).

These developments point inexorably in the same direction. As the web marches on and data of all types and qualities become increasingly ubiquitous, the issues are not only about whether we can keep them secure but also about confronting profound issues about who owns the data, where they are, how accurate they are, and who is accountable for them.

\section{The Known Unknowns of Cybersecurity}

There is no doubt that the biggest operational challenge to e-government is cybersecurity, including threats to identity, privacy, and data systems. 
Adequate privacy and data protection, and the trust these support, are crucial for reaping the benefits of e-government. If they are in place and work well, they can provide stable, predictable, and confidence-building frameworks. In fact, these are key for any activity using information and communications technology (ICT) across society, whether in the public, private, or civil sectors, so should not be seen in isolation. But if they are not, it can have negative effects on usage. According to the European Commission (2009, p. 1), "Only 12\% of EU Web users feel safe making transactions on the Internet, while 39\% of EU Internet users have major doubts about safety, and $42 \%$ do not dare carry out financial transactions online." Ongoing news reports about lost credit card data and private information in both the private and public sectors are not likely to improve this image. For example, according to a November 2007 BBC News report, two password protected computer disks holding the personal details of all families in the United Kingdom with a child under 16, 25 million people in total, went missing. The package had not been recorded or registered and has never been found since being physically transported between two departments. This has been one incident among many severely questioning the way government handles sensitive data. There are also increasing numbers of malicious hacker attacks, financially motivated breaches, and even policy motivated efforts to shut off information, such as during the attacks on Estonia, the Iranian demonstrations in 2010, and the 2011 uprisings in the Middle East. We know a lot about the main cybersecurity threats, yet a lot less about how to meet them. As the foremost duty of government is to protect its citizens, the public sector must build highly effective and integrated systems to protect against crime, espionage, terrorism, and war in cyberspace.

Government's response to cybersecurity issues has, however, generally lagged the private sector, despite it arguably being more important, and, according to a 2008 Organization for Economic Cooperation and Development (OECD) report, there is limited availability of data on public sector efforts. Even in highly advanced e-government countries like Norway, only a minority of public administrations have been offering secure ways of communicating with their websites, despite many surveys showing that fears of data insecurity are perceived by users as the biggest deterrent to their use of e-government. However, it is also worth noting that the cybersecurity response is highly variable, for example central governments 
are much more likely to have adequate measures in place than local, obviously reflecting the size of populations involved and the resources available. But many e-government services are provided at the local or regional levels and the amount of information provided by these entities is rapidly increasing. One of the challenges of cybersecurity in e-government is that the public sector is characterized by a large amount of operational independence and "siloization" among its various parts, something not seen in the private sector to the same extent.

Security in government's cyberspace is thus of paramount concern, and it is clear that current systems, both organizational and technical, are not always meeting the challenge. Future solutions will also likely require solutions very different from those of today's systems that are predicated on relatively stable, well-defined, consistent configurations, contexts, and participants in security arrangements. A new paradigm is probably needed characterized by "conformable" security, in which the degree and nature of security associated with any particular type of action will change over time, with changing circumstances and with changing available information. In this endeavor, it is likely that the public sector will have to deal with challenges in five areas: privacy, trust, data security, loss of data control, and human behavior.

\section{Privacy}

Cybersecurity initiatives need to consider privacy implications that in many cases can significantly compromise their likely efficacy. For example, privacy and data protection will need conformable security systems, adapted to the changing access needs and identities of people and organizations. These systems will also need to operate across national borders, which will require not just political agreements but also data structures and standards that are compatible. Data security will also be improved by giving users much greater control over their own data and their own (often) multiple identities, for example, through trusted third parties. For services that can operate across borders, well-functioning identity and authentication systems will be vital. Information assurance is also needed as a holistic approach incorporating risk management, given that no system can provide complete security. Long-term data preservation and access are also 
important given the fast-changing technical formats and the huge increases in data generation expected.

Privacy needs to be upheld, for example, through regulation and international agreements like the European Data Protection Framework, including appropriate data ombudsmen, custodians, or trusted third parties. Care should be taken to avoid "mission creep," when data are used for purposes not originally intended, or the "race to the bottom" in interagency or cross-border data sharing by a reversion to the standards of the weakest member. User needs and trust must be built on an understanding of real human behavior when using data, as well as on technical requirements.

\section{Trust}

The technical aspect of cybersecurity may turn out to be the easy part. Clearly, understanding and catering for, what some call irrational or schizophrenic, human behavior can be a real challenge to cybersecurity.

Trust is a critical issue and is built through information minimalization (i.e., using as little data as possible to perform a task), and informing users or obtaining user consent when accessing and processing their data by enabling users to trace, own, or control their own data. Trust is also built by properly managing, explaining, and minimizing the risks of data loss or leakage. Trust is notoriously difficult to build but can be very quickly and devastatingly destroyed by one single breach. This underlines the need to consider trust as multidimensional. Clearly, for maximum benefit, users need to trust their government or service provider, but it is also becoming increasingly important for governments to trust users, for example, by allowing them to deploy public sector data and engaging them in policy development and decision making. E-government will also require personalizable and context-relevant ICT, customer (or citizen) relationship management systems, and decision-support and forecasting systems based on intelligent knowledge management and archiving. Personal e-governance modules/spaces are likely to become important that are context-sensitive, intelligent, and personalizable, also for tracking and tracing service progress. 
Although much of the debate about cybersecurity, certainly in the mainstream media and in everyday discourse, is far from rational, informed, or accurate, it is also very difficult to be dispassionate. Just as in the physical world also in cyberspace, one person's terrorist is another person's freedom fighter-literally, in the case of WikiLeaks and Julian Assange. On the one hand is the view held by many governments that the more citizen data available the better citizens can be helped and protected. Compare this with the opposite view held by many citizens of fear of the surveillance state with nowhere to hide. If governments hold too much data, this intrudes into citizens' private lives. Moreover, governments have a poor track record of keeping data safe, and there are many examples of data misuse by government, either knowingly or unknowingly. However, at the same time, the same citizens who worry about "big brother" government, willingly provide private companies, which they know are only concerned with making money out of them, with much more personal data than they ever give governments. Many also scatter even more personal and often intimate details about themselves on social networking sites. Perhaps citizens perceive governments as so big, monolithic, and pervasive that any data misuse will have huge consequences, while the private sector or social networking sites are so differentiated and variegated in comparison that data misuse cannot be of much importance. Professionals know this is very far from being the case.

\section{Data Security}

Who owns data can be a deeply philosphical question, but it is of real practical importance when it comes to cybersecurity because it determines who can (or should) secure it. For example, do individuals or organizations own the data they give to governments or which governments collect, or does government own data once in its possession? Perhaps of greater importance is the right to use data regardless of ownership, especially if they have economic or other value. Recent studies in the United Kingdom, such as one by Newbery, Bently, and Pollock, and by the European Commission have shown that "public sector information" (PSI) has clear and significant economic value that can be sold to commercial or other organizations to provide revenue streams for government. This has been the norm in most advanced 
countries for many years, but a concerted "free-our-data" campaign in the United Kingdom over the last few years has led to most government agencies releasing PSI in machine-readable and easily accessible formats for free use by anyone. The main argument being that even greater economic value for society as a whole is thereby created when entrepreneurs of all types can develop new offline products (such as business services around economic data), as well as new online smart services (or "apps") that may in their own right be given away freely. Freeing up data in this way is now part of a burgeoining "open government" movement, such as the UK's Transparency and Accountability Initiative 2010, although still only significant in a few countries.

Many argue that data security will be improved by giving users much greater control over their own data and their own (often) multiple identities, as they then take a direct interest in ensuring its safety and accuracy. For example, in 2003, a Data Protection Act was passed in Estonia covering information relating to an identified natural person's physical, mental, physiological, economic, cultural, and social characteristics, relations, and associations. On request, the natural person has a legal right to access all personal data relating to him or her, the purposes of these data, their categories and sources, and third persons or categories to whom transmission of the data is permitted. According to the country's Personal Data Protection Act, the person has the further right to request the termination of processing of their personal data, to correct in the case of errors, and to block or erase their data, through the Data Protection Inspectorate or courts. Issues surrounding the security of the person's home computer when examining their data on the official website are not addressed in this legislation, as this is largely beyond the government's control, but are felt to be of less concern as any data leakage would be piecemeal rather than wholesale. However, very few countries have data ownership and rights provisions as well developed as Estonia, and this is likely to skew the way governments implement cybersecurity and the attitude citizens have about the issue.

\section{Loss of Data Control}

There are burgeoning and very beneficial examples of outsourcing where cybersecurity does not seem to have been compromised, but 
the very fact that data are widely shared, no longer under direct government control, and moved around increases the risks. These arise from technical incompatibilities and because of the often very different organizational and workplace cultures and intentions involved, where it becomes increasingly difficult to maintain common control and to monitor standards.

Introducing e-government implies the need to completely redesign both organizational structures (essentially, smashing the silos) as well as data architectures to enable the sharing of services and resources across and between public administrations. This is increasingly taking place in shared service centers and also covers ICT applications, e-government building blocks, information and data, as well as common business processes. This can also facilitate outsourcing to other actors, including outside the public sector, if costs can be cut. However, a major criticism is that costs may not be saved in the longer term, it may reduce quality, and certainly leads to loss of control by governments that are, in the final analysis, democratically accountable unlike private contractors.

It is clear, however, that significant disruptions do take place. According to Davenport (2005) we are on the edge of a major move toward the ICT-based commoditization of large numbers of business processes, and this will also profoundly affect the public sector, making outsourcing as well as greater user involvement much more likely. All types of business processes, not just in relation to designing and delivering services, but also from developing software, through hiring personnel to at least some aspects of policy modeling and development through automatic modeling, scenario, and simulations, are being analyzed, standardized, and routinized, and this knowledge is being codified and facilitated by ICT. This could lead to process commoditization and outsourcing on a massive scale. The widespread use of ICT undoubtedly means that the public sector must grapple to avoid the simultaneous loss of knowledge and control over basic processes and over the competencies, decisions, and policies needed to support these and which lie at the basis of all public services. There is a need to better understand which aspects of the public sector's activities can and should be codified, commoditized (e.g., through ICT) and outsourced or "networked" with other actors including both private and civil sectors, and as increasingly seems likely, with users. The jury is still out on all these 
issues, but in the context of the financial crisis their importance is dramatically increasing again as governments attempt to cut costs.

\section{The Mother of All Known Unknowns-Human Behavior}

Building in technical resilience with "graceful degradation" when under cyber attack, and ensuring rapid reconstitution of mission-critical functions, are key on the technical side. However, the main known unknown of cybersecurity, because we rarely stop to think about it and it is so unpredictable, turns out to be more important than the purely technical issue of how to make it work-human behavior. Most accept that security can never be perfect, but the reasons need greater scrutiny, especially when it also becomes clear that there is an inverse relationship between the use of systems (which we obviously want to encourage) and the security of those systems. It is like the old adage, that if you want to be completely safe and take no risks stay in bed all day- though this says nothing about earthquakes, so even that is not risk free. But that is no way to run a society, develop an economy, let alone live a life. Human behavior, whether rational or not, lies at the core of cybersecurity-how people think about their identity, data about their identity, who owns it, has access to it, and how it is used. We do know that a better understanding of the relative risks of cyber insecurity compared to the benefits of system use is the core challenge, but we do not yet know much about achieving good balances. This is particularly the case in the government sector, compared to the private sector, where it is not possible or desirable to employ market solutions to find the balance. It needs to instead be explored through trial and error, evidence collection, as well as the conscious application of ethical and democratic principles.

\section{Government Loses Control-Who Is Now in Charge and Why It Matters}

With the adoption of Web 2.0 tools and approaches, many governments are moving into the "Governance 2.0" paradigm that enables "coproduced" services in which users actively cooperate with service providers, and "self-created" services in which it is mainly users who determine the service. This can also lead to "crowd-sourcing government" where content and inputs are sourced from a wide range of users and others actors who have particular knowledge and interests 
not possessed by the government. The cybersecurity concern for the public sector and for citizens and businesses is how these data are dispersed, shared, and used, as well as by whom. Perhaps of even greater importance, is it possible to find out who is using the data? Losing control is one thing, but not knowing who now has control compounds the problem. For example, specific parts of Australia still remain blurred on Google Earth. Google says that it removed the high-resolution photos due to a problem with one of the image providers, but IT Security, an online publication, point to fears that the maps could be used as a terrorist tool. Some of the blocked areas include (or have included at some point) The Garden Island Naval Depot, the Lucas Heights Reactor, Parliament House, and the Australian Defense Force headquarters in Canberra.

Less of a security issue but still of concern to the public sector is not only are the data secure but also can they be preserved and made available for authorized use in the long term, given constantly changing data formats and standards. Here again, the need for a trade-off between security and use is evident. For example, data preserved on floppy disks 15 years ago today require specialist intervention resorting to museum artifacts to access them. Cloud computing may help as it potentially enables data and other resources to be dispersed potentially in multiple servers somewhere on the Internet. But even if this solves the "where" challenge, long-term preservation still requires standards and formats to be accessible in the long term.

When data preservation is outsourced to a specialist private company, or when e-government services, for example, can be automatically delivered from the "public cloud," there are profound issues of control and ownership, including possible loss of accountability and democratic oversight. Another example in the Netherlands shows not only loss of government control, but also of usurpation of everything a government does because others can access or even create their own data relevant to an erstwhile public function. This involves the combination of Web 2.0 tools and consumer electronics, like high-resolution recording equipment, sensors, and cameras that are increasingly available in the high street to everybody and not just professionals. The complaints by people who live near Schiphol Airport in Amsterdam about aircraft noise levels were ignored or dismissed by the public authorities, leading to the residents developing their own 
measurement system based on sensor technology linked to a computer and the Internet. The system has been installed in the gardens of the protesters and records the level of aircraft noise. This is captured electronically, collected, mashed up with other data and applications, and published on their own website, http://www.geluidsnet.nl/en/ geluidsnet/. This illustrates an increasing trend whereby professional hardware and software are becoming commodities available to everyone to design and implement their own "user-driven" services, in this case showing how public agencies can have their competence and reliability both undermined and usurped. After some battles, the public authorities accepted that the residents' system was more accurate and reliable, and this has now become the de facto service. Perhaps some backhanded benefits for government here could include the fact that by losing control they might also lose responsibility, both political and financial, although that remains a challenge to be negotiated.

Another aspect of loss of control by government is the fairly disappointing use of e-government portals and growth of alternative user-driven tools. For example, the direct.gov.uk portal in the United Kingdom acts as a gateway to all public services and has often been praised as world class. However, citizen use has been admittedly low, according to William Perrin (2008) at the Transformational Government Unit in the UK Cabinet Office, and, as evidenced by several sources, including the European Commission, OECD, and McKinsey (2009), a consultancy, this is a common problem for e-government portals around the world. Instead, whether governments like it or not, access to public sector data is becoming dispersed, both by the rise of third-party providers, but also by governments. In fact, some countries are now moving away from the portal concept to multichannel service delivery methods that offer the citizens direct access to local services, simplifying the services and reducing the time taken to carry through a service request by eliminating the number of steps needed to complete a transaction. Such moves illustrate the "no-wrong-door" approach providing direct service access wherever the citizen might be on the Internet. In a recent unpublished survey undertaken by the author, experts and practitioners cited a number of reasons why the dominance of portals is coming to an end: "Why go to a portal first when I am already somewhere else on the web? I want to go direct to the service I need." "Everything (services, applications, 
platforms, infrastructure) is-or will be-in the cloud anyway as a 'service,' so just use Google or other search engines to find what you need." "Do we hang on to grandiose portals because they are a showcase-just like an imposing town hall-but what do they really do for all that money?"

Loss of government control of data is also likely to lead, in the e-government services context as for other commercial and personal services, to organizations, enterprises, and individuals increasingly making their data (content and functionalities) available in the cloud rather than via a portal or even a website. This means that service users will be able to create their own content and services on their own platforms typically through avatars or automatic electronic agents. Going through the "front door" of a website will probably be seen by an increasing number of users as an extra unnecessary step. There is also rapid growth of new ICT channels, like mobile and digital TV, all of which is leading to the proliferation of a multitude of channels and platforms, where portals and websites constitute one, probably small, part of the offering.

These developments are likely to mean that cybersecurity could become even more relevant, because even if the web is declining in importance, increased ICT usage across diverse channels makes it more important overall as well as more challenging for e-government. Alongside high-profile attacks on government websites (with the White House, the Pentagon, the cyber attack on Estonia, all being prominent examples), this could, in turn, scare off many users. This would further decrease trust in using e-government and might tempt users to demand a return to more traditional face-to-face services that in their view are more secure. The fact that this view is often entirely wrong, because paper records are more easily perishable, lost, or destroyed, and information much less accessible when needed, might be difficult to establish.

What e-government is good at doing is making data available as services to users in ways never before imagined, and there are many good examples of this such as the FixMyStreet website, http://www.fixmystreet.com/, in the United Kingdom. However, it is not always government doing it, as in this example where a third sector organization collected data from all authorities about their responsibility for maintaining and repairing streets and local neighborhoods-everything 
from broken paving stones to graffiti and rubbish. These data are then used to automatically direct complaints, simply accompanied by a post code, to the responsible authority, making this e-government service one of the most used in the United Kingdom.

Another 2011 example, also from the United Kingdom, is the website availability of crime statistics on local maps, intended as a service to citizens. According to the Guardian, a British paper, immediate problems arose that had not been anticipated. First, there were fears that house prices in high crime areas would fall with some home owners threatening to sue the relevant agency for their loss. Second many of the data were wrong or badly calculated or mislocalized, often giving completely inaccurate impressions. Scale is very important, not just of data presentation on the map but even more of collection and allocation. Issues arose around how the data were collected, who did the data collection, and how they were recorded and where. The apparent objectivity of data showed again to be subject to the machinations of less than perfect human behavior that became magnified by ICT. The advantage of seeing these problems in the public sector does, however, raise awareness of similar problems that almost certainly exist in private commercial services that hide, or attempt to hide, them. It also makes us realize that such problems have always existed, and one advantage of digitization is that it makes them transparent even if it might magnify them.

\section{Who Gets In and What Gets Out When Government Opens the Door?}

As well as coordination and integration within the public sector, there is an increasing trend toward cooperation with other actors, from both private and civil sectors, as well as with users. All this is generally very beneficial to all involved. Although the private sector has for many years acted as an important partner to government, the civil sector is now also starting to become a significant and often new source of resources and expertise for undertaking public sector tasks and delivering services. So, in addition to public-private partnerships (PPPs) the trend is also toward public-civil partnerships (PCPs). For example, the voluntary sector and social entrepreneurs, especially when they function as intermediaries between the government provider and 
the constituent user, can contribute grassroots resources, knowledge, innovation, and even useful competition.

Government is thus becoming collaborative, open, and porous, in ways and to an extent not seen in other sectors, and this could lead to beneficial disruption of the way in which the public sector operates and the responsibilities it has. First, in order to deliver better services and better governance, technology is helping to turn the public sector inside-out, by exposing the way it works and pushing its activities out into society. For example, e-government enables civil servants and politicians to roam free of the confines of the town hall and engage directly with citizens on the streets or in their homes and with businesses on their own premises, while always being in touch with the intelligence and knowledge they need in the back-office. Second, the technology is helping to turn the public sector outside-in by inviting commercial, civil, and constituent actors inside to participate in designing and delivering services as well as providing them with tools to join in the making of public policy and decisions.

All this generally brings many benefits, but there are also dangers or at least challenges that should make us stop and think. When government is just one player among many in the public sphere, which now also legitimately consists of private and civil sector actors, new forms of accountability need to be found. A pair of researchers, Bovens and Loos (2002), addressed this issue when they described the shift from legality to transparency. A new form of accountability is needed when governments have to share data, power, and responsibility, for example because of the processes of horizontalization, deterritorialization, and scalability. Horizontalization allows the partial shifting of the production of generally binding rules away from the traditional legislative power to other regulatory parties that may have no democratic legitimacy, such as independent administrative bodies (cf. quangos), umbrella organizations, and interactive policy partners. The process of digitization can make it possible for all authorities, including those in the private and civil sectors, to move faster than legislators in the public sector and in parliament.

Deterritorialization refers to the fact that the many challenges and issues faced by government across borders (e.g., trade, pollution, migration, crime, etc.) can present the national legislature with accomplished facts over which it has no immediate control. Globalization 
and rapid change and turbulence cause the formal legislature to lag behind and require new flexible forms of regulation. The 2008 financial crisis and crash were enabled if not caused by the "big-bang" in the mid 1980s when the financial services sector went digital enabling billions of dollars to be moved around the globe in a millisecond. For both horizontalization and deterritorialization, cybersecurity needs not only to cope with public sector or national data dispersion and systems but also with global threats increasingly in real time. This implies not just technological complexity but also political, organizational, cultural, and behavioral complexity on a massive scale.

The limits of government action are increasingly visible. Complex policy challenges ranging between international and personal levels-in such diverse areas as climate change, aging populations, and obesitycannot be "solved" by government action alone. Tackling them effectively will require the concerted efforts of all actors in society including individual citizens. Governments everywhere are under pressure to do more with a lot less. Most are working hard to deliver effective policies and services at least at cost to the public purse; many are trying to leverage resources outside the public sector. Last but not least, governments are seeking to ensure and maintain high levels of public trust, without which government actions will, at best, be ineffective and, at worst, counterproductive. At the same time, more educated, well-informed, and less deferential citizens are judging their governments in terms of their democratic, policy, and service delivery performance.

The role of the public sector may be to retain competence and control over these high-level issues in the public interest and with the public good and public value in mind. The danger of not doing so could be that the public sector, as we understand it today, could disappear or shrink to a rump of only doing things that the market is not interested in, while everything is commoditized, outsourced, and privatized, or passed to the whim and partiality of charitable organizations. Such developments are already apparent in the United States. This could be one of the biggest challenges to public service and to the public service ethic as we know it today. In such a scenario, protecting the public sector from cyber threats will be even harder as data will be dispersed. This can also mean that private sector entities, in practice, would need to protect public sector data. Would they have the bottom line as their prime concern or the public good? However, 
despite the problems raised by loss of government control of data, some would argue that dispersed ownership, control, and use of public sector data can be beneficial as it mitigates the concentration of power and increases responsibility, creativity, and innovation. This very dispersion may also improve cybersecurity because, although the risk of having a security breach clearly increases, any damage is likely to be much less and more manageable than a low-risk but highly catastrophic breakdown in security of a highly centralized system that controls most if not all data. Once again, it is clear that the core cybersecurity challenge is not technical (however, important and intractable this is) but is the need to balance cybersecurity with system use in the context of often unpredictable organizational and individual behaviors and needs.

\section{Back to Basics: Trust, Transparency, and Accountability}

Trust, transparency, and accountability are arguably the three biggest challenges confronting successful e-government, and all are inextricably interlinked. Without trust in the public sector, online government will fail. It is a truism that trust is difficult to grow and easy to degrade, so it is imperative to find ways to reverse this trend. Trust and mistrust go hand-in-hand and need to be balanced. Trust reduces transaction costs, but a healthy mistrust encourages constructive criticism and debate. The trick is to know the difference. Governments can assist in this by maximizing transparency and openness so citizens can see how decisions are made, who takes them, and why. Suitable opportunities to challenge the decision-making process are also needed within clear rules.

As noted by the Hansard Society (2008), a UK nonprofit, although ICT, can be very important for increasing participation, it is crucial to have clear, transparent, rules-based accountability for all forms of participation in order to reconnect disaffected voters with politicians. Apart from ICT being used to give access to public information (which is a very important aspect of e-participation), ICT can support moves toward much more extensive transparency as part of the concept of open government. For example, enabling users to trace every interaction within the public administration right down to the name of the civil servant who is dealing with their query or case in real time. 
In another example, as part of a move on from e-procurement, the UK government has recently set up a website showing the budgets and expenditure of all government agencies, and this is now being rolled out across local governments, following the lead set by Recovery.gov in 2009, the U.S. government's official website that provides easy access to data related to recovery act spending and allows for the reporting of potential fraud, waste, and abuse. Developments like this could be part of a move toward a situation, not just of transparency of information and of services, but also transparency of the purpose, actions, processes, and outcomes of government. This would mean that all could potentially have access to (near perfect) knowledge about what is going on, and the impact this has or is likely to have. As noted by a pair of researchers, Blakemore and Lloyd (2007), this would make it possible to relate decisions and actions very precisely to the whole set of diverse (sometimes contradictory, sometimes complementary) needs of all actors. The publication of heretofore confidential information by the WikiLeaks website is a powerful example that this trend is happening whether governments like it or not.

System and data transparency could enable users and civil servants to trace and track requests and cases through the public sector in order to follow progress, know which part of the system is currently responsible, and to better foresee and circumvent bottlenecks or roadblocks. The placing of responsibility (and intellectual property rights [IPR] where relevant) could be critical, especially in relation to users who, by way of their status or situation, may not be able to exercise their own responsibility, such as children, the elderly, the handicapped, and so forth. This will also allow users to become involved, to be better informed, and to be better able to exercise some control for their own benefit.

As noted by the European Transparency Initiative (2005), transparency is often the basis for trust. Transparency in the public sector actually implies really being able to "both see and get what we pay for" and to make this visible to all. It should also imply the end of invisible, divisive, Kafkaesque bureaucracies not knowing what they are doing except for serving their own ends. Transparency can also save time and money through reducing errors, pooling resources and knowledge, reducing duplication, and promoting cooperation. Transparency also reduces corruption. It is important to emphasize 
that although there is a continuing need to increase users' trust of government across all public sector tasks, governments also need to increase their trust in users so that they, with support and within clear guidelines, will be able to participate responsibly. Such trust is potentially manifest in many ways. For example when governments make available local crime data including in machine-readable format for re-mashing, they trust society to use these wisely to inform rather than a scaremonger. Similarly, when governments open up the decision- and policy-making processes to citizens, two-way trust is required. Clearly there is a learning curve for both governments and citizens in how to handle and interpret freed-up data sensibly and responsibly, and how to avoid the dangers of misuse in the many forms this can take.

Although it is clear that the widespread release of public sector data can have immense benefits, there are almost certainly legitimate interests that should be protected from total transparency and openness. For example, there are undoubtedly legitimate privacy needs and interests of citizens and businesses when their data are used by government. Just as important, however, are the interests of civil servants and politicians, especially during the decision- and policymaking process, for example from intrusive exposure and monitoring that could result from all their actions and decisions being made totally transparent. This could bring about stress and too much focus on measurement and performance at a personal level, and lead back to an overly bureaucratic stance, working strictly to rule-books rather than being flexible and prepared to take measured risk with policy ideas. It could also provoke an unwillingness to make decisions, or to take responsibility for them. According to a 2007 article in the Guardian, one top-ranking civil servant in the UK government is quoted as saying "I would never now write down advice to ministers," and accuses the 2007 Freedom of Information Act of "impeding the effective work of government, not least because officials face 'frivolous' or 'time-consuming' fishing expeditions from journalists, campaigners and citizens."

Accountability flows from responsibilities as well as from openness and transparency. It is also related to ethical considerations that are, both in theory and practice, highly important in the public realm. There are different types of accountability. First, political 
accountability should be exercised by politicians and democratically elected representatives. Second, administrative accountability rests on civil servants individually as well as on the public sector as an institution. This also includes the likelihood of changing accountability when private sector and civil organization partners are involved in undertaking public sector tasks, such as policy making or delivering services. Third, there is user accountability in not misusing or abusing public sector services or facilities, as well as in participating in legitimate and responsible ways. All these relate to responsibilities. Fourth is the general ethical and moral accountability of all actors, including citizens, businesses, communities, and the public sector. If things go wrong, the boundary of powers, accountability, and responsibility between government and user becomes important, so there also needs to be an open and fair appeals procedure. Formal agreements may need to be entered into, such as a Service Level Agreement (SLA) or citizen charter, both for individuals or groups of users, as exemplified by Burgerlink, the e-government citizens charter in the Netherlands (Burgerlink, 2006). Accountability needs to be clear and traceable, so that if things go wrong it is clear who is responsible and how the situation can be resolved. Simplicity helps all of these issues by increasing understanding and awareness of the democratic process. However, as this chapter has shown, e-government often leads to increasing complexity and massive blurring between roles and tasks when so many actors are involved and so many voices are clamoring to be heard.

\section{How to Swim in an Ocean of Insecure Data}

The purpose of this chapter is not to provide answers for tackling cybersecurity threats to e-government, but five main challenges do emerge clearly from the issues reviewed in this chapter:

1. The public sector is characterized by a large amount of operational independence and "siloization" among its various parts, which makes tackling cybersecurity extremely challenging and probably more challenging than in the private sector.

2. Important public data are now being created, held, and applied by actors and individuals outside of government, so that the 
definition of public sector security must be expanded and rethought.

3. Human behavior, whether rational or not, lies at the core of cybersecurity-how people think about their identity, data about it, who owns it, who has access to it, and how it is used.

4. There is an inverse relationship between the use of systems (which we obviously want to encourage) and the security of those systems, but we do not yet know much about achieving good balances.

5. Users of e-government may be in need of just as much cybersecurity protection from government as government is from third parties, particularly where governance regimes are incompetent or corrupt, but the issue is more general and related to the proper role of the public sector vis-à-vis other actors.

The consequences of these challenges are that coordination and control become increasingly difficult and that the range of cybersecurity threats that need to be addressed have multiplied in scope and scale for all actors in the public realm. Some responses to the first four challenges are obvious. Clearly, government-wide, end-to-end strategies for meeting cybersecurity challenges must be developed and applied, working closely with the private sector that will provide some of the solutions, but also need to be agile and aware of the ever-changing landscape of threats. International cooperation and frameworks need to be negotiated and put in place, given that there are no political borders to such threats. Perhaps most important of all, cultural changes within organizations need to be driven through in relation to awareness of cybersecurity issues, responsibility for tackling them, and the working practices that underpin these.

Other responses flow from these general tenets, as noted by Booz Allen Hamilton (2009), a consultancy, and Fed Tech magazine, to include the need to improve the overall governance and coordination of cybersecurity, simplification of processes and rules, and the need to foster appropriate talent and skills in the public sector. The 2010 survey undertaken by TechAmerica noted that "a high percentage of security breaches occur because internal users are careless or fail to 
follow procedures" (p. 8). Local governments are probably even more threatened than central administrations due to their relative lack of resources and expertise, but even here much can be done. According to a nontechnical guide to cybersecurity published by the Multi-State Information Sharing and Analysis Center in collaboration with the U.S. Department of Homeland Security, this includes recognizing the problem; designating responsibility; protecting essential hardware, software, and information; controlling access; improving training and awareness; and ensuring safe disposal.

Responses to the fifth challenge are less straightforward and may need a slowly evolving mindset change to tackle. However, as pointed out by this author in a 2010 article in the European Journal of ePractice; much evidence now points to the benefits of establishing neutral trusted third parties to stand between governments and data providers on the one hand and citizens on the other, and to ensure that the interests and rights of all stakeholders are fairly upheld. Such third parties could be commercial, civil, or even arms-length government agencies but need to be legally and operationally independent and seen to be so. They might advantageously perform some of the following tasks:

- Act as a "champion" and "watchdog" for users in relation to using data and engaging in policy and decision making, thus act as a sort of "ombudsman" for users vis-à-vis the government.

- Agree and publicize a citizen charter of rights and responsibilities for users in using public data and in public engagement, building on what is there already in law or regulation, and open these to debate and amendment by users.

- Identify and implement frameworks for real motivation, incentives, and rewards for user engagement in service design and policy participation.

- Continuously monitor the potential risks and inform users about these, as well as offer possible solutions and assistance.

- Provide both proactive and passive moderation on Web 2.0 media, as well as help frame debates in a neutral and balanced way, if requested and appropriate. 
- Monitor and uphold users' privacy and data protection rights vis-à-vis governments and other interests. This would include preventing the misuse of personal data whether provided consciously by users or collected automatically during service use.

- Ensure that all "public" services, whoever provides them, identify the provenance of all data and other sources used, while complying with other open source requirements concerning relevant ownership and liability. This should also include monitoring and referral functions to ensure that any service developed for public use lives up to agreed standards of accuracy, quality, and the "public good."

- Despite the immense potential benefits of releasing all types of public data, there is a danger of data overload and data misuse. Data, like statistics, can be seriously corrupted to mean anything anybody wishes. A trusted third party should monitor and provide neutral and transparent guidance as well as intervention on such issues.

It is important to put in place safeguards like these to ensure that governments or any actors do not inappropriately manipulate other actors. This will also be facilitated by ensuring that public data and processes are open and transparent, as this balances power across all actors and mitigates misuse and corruption.

\section{References}

Author's interview with William Perrin, Transformational Government Unit, UK Cabinet Office, London, 5 June 2008.

BBC News. November 20, 2007: http://news.bbc.co.uk/2/hi/7103566.stm.

Blakemore, M., and Lloyd, P. (2007). "Trust and transparency: Pre-requisites for effective eGovernment," Citizen-Centric eGovernment Think Paper, 2007: 10.

Booz Allen Hamilton. (2009). "Cyber IN-Security: Strengthening the Federal Cybersecurity Workforce,” Partnership for Public Service, July 2009: http://www.ourpublicservice.org.

Bovens, M., and Loos, E. (2002). "The digital constitutional state: Democracy and law in the information society," Information Policy, Vol. 7, No. 4, 2002, pp. 16, 185-197.

Burgerlink (2006). (Workbook e-Citizen Charter,"Version 2.2 (December 2006); http://www.burgerlink.ml/Documenten/burgerlink-1.0/live/binaries/ burgerlink/pdf/citizen-charter/workbook-e-citizen-charter-english.pdf. 
Capgemini, IDC, Rand Europe, Sogeti, and DTI. (2010). "Digitizing Public Services in Europe: Putting ambition into action-Ninth Benchmark Measurement," for the European Commission, Directorate General for Information Society and Media, December 2010.

Davenport, T.H. (2005). “The coming commoditisation of processes," Harvard Business Review, June 2005, pp. 101-108.

Digital Agenda website: http://ec.europa.eu/information_society/newsroom/ cf/pillar.cfm?pillar_id=45.

European Commission (2009). "Consumer Rights" Commission wants comsumers to surf the web without borders.”IP/009/702, 5 May 2009: http:// europa.eu/rapid/pressReleasesAction.do?reference=IP/09/702.

European Commission workshop. June 16, 2009. "i2010 eGovernment Action Plan Progress Study (SMART 2008/0042)” Brussels, hosted by FG INFSO, European Commission.

European Journal of ePractice. (2010). "Government 2.0-Hype, Hope, or Reality?” Number 9, March 2010: www.epracticejournal.eu.

European Journal of ePractice. (2011). "e-Government for the economic crisis," Number 11, March 2011: www.epracticejournal.eu.

European Transparency Initiative, IDABC European eGovernment News Roundup. November 2, 2005, No. 116.

Givans, N. (2009). “Cybersecurity and the government CIO,” June 11, 2009. http://fedtechmagazine.com/article.asp?item_id=655.

Guardian newspaper. June 15, 2007.

guardian.co.uk. Online crime maps crash under weight of 18 million hits an hour by A. Travis and H. Mulholland: http://www.guardian.co.uk/ uk/2011/feb/01/online-crime-maps-power-hands-people.

Hansard Society. (2008). "Digital Dialogues 3": http://www.hansardsociety. org.uk.

IT Security: http://www.itsecurity.com.features/51-things-not-on-googlemaps- 071508/.

ISTAG (Information Society Technologies Advisory Group). (2002). "Trust, dependability, security and privacy for IST in FP6." The European Commission: http://www.cordis.lu/ist/istag.htm.

McKinsey. (2009). E-government 2.0, number 4, summer 2009 edition of McKinsey on Government, retrieved December 8, 2009, from: http:// www.mckinseyquarterly.com/Public_Sector/E-government_20_2408.

Millard, J., and Horlings, E. (2008). "Research report on value for citizens: A vision of public governance in 2020," for the European Commission eGovernment Unit, DG INFSO: http://ec.europa.eu/information_society/activities/egovernment/studies/docs/research_report_on_value_for_ citizens.pdf.

Millard, J. (2009). "eParticipation recommendations-Focusing on the European level." Deliverable 5.1d\&e: http://islab/uom/gr/eP/index/ php?option=com_docman\&task=cat_view\&gid=36\&\&Ite.

Millard, J. (2010). "Government 1.5-Is the bottle half full or half empty?" European Journal of ePractice, Number 9, March 2010: www.epracticejournal.eu. 
Multi-State Information Sharing and Analysis Center. (undated). "Local government cyber security: Getting started-A non-technical guide." Published in collaboration with U.S. Department of Homeland Security, National Cyber Security Division: http://www.msisac.org.

Newbery, D., Bently, L., and Pollock, R. (2008). "Models of public sector information provision via trading funds." Cambridge University, February 26, 2008.

OECD. (2008). "Measuring security and trust in the online environment: A view using official data."Working Party on Indicators for the Information Society, Directorate for Science, Technology and Industry, Committee for Information, Computer and Communications Policy, DSTI/ICCP/ IIS(2007)4/FINAL, 21 January 2008, Paris.

OECD. (2009). Rethinking e-Government Services: User-Centred Approaches." Paris, October 2009.

Personal Data Protection Act (RT I 2003, 26, 158). Estonia: http://www. dataprotection.eu/pmwiki/pmwiki.php?n=Main.EE\#robject.

TechAmerica. (2010). "Tranparency and transformation through technology." Twentieth Annual Survey of Federal Chief Information Officers, March 2010.

Transparency and Accountability Initiative. (2010). “Open data study.” May 2010; UK Cabinet Office (2009, June 10); The PSI Directive put in place in 2003 (IP/02/814): http://ec.europa.eu/information_society/newsroom/ cf/itemdetail.cfm?item_id $=4891$

Ubaldi, B. (2011). "The impact of the economic and financial crisis on e-government in OECD member countries." European Journal of ePractice, Volume 11, e-Government for the Economic Crisis: http:// www.epractice.eu.

United Nations. (2010). "e-Government Survey 2010: Leveraging e-government at a time of financial crisis." Department of Economic and Social Affairs, New York: http://www2.unpan.org/egovkb. 